\title{
Comparison of treatment costs of laparoscopic and open surgery
}

\author{
Jacek A. Śmigielski ${ }^{1}$, Łukasz Piskorz ${ }^{2}$, Włodzimierz Koptas ${ }^{1}$ \\ ${ }^{1}$ Department of Thoracic, General and Oncologic Surgery, Medical University of Lodz, Lodz, Poland \\ ${ }^{2}$ Department of Surgery, Bonifratres Hospital Lodz, Lodz, Poland
}

Videosurgery Miniinv 2015; 10 (3): 437-441

DOI: $10.5114 /$ wiitm.2015.54055

\begin{abstract}
Introduction: Laparoscopy has been a standard procedure in most medical centres providing surgical services for many years. Both the range and number of laparoscopic procedures performed are constantly increasing. Over the last decade, laparoscopic procedures have been successfully applied both in emergency and oncological surgery. However, treatment costs have become a more important factor in choosing between open or laparoscopic procedures.

Aim: To present the total real costs of open and laparoscopic cholecystectomy, appendectomy and sigmoidectomy. Material and methods: Between 1 May 2010 and 30 March 2015 in the Department of Thoracic Surgery, General and Oncological Surgery, Medical University of Lodz, and in the Department of General Surgery of the Saint John of God Hospital, Lodz, doctors performed 1404 cholecystectomies, 392 appendectomies and 88 sigmoidectomies. A total of $97 \%$ of the cholecystectomy procedures were laparoscopic and 3\% were open. Similarly, 22\% of total appendectomies were laparoscopic and 78\% were open, while 9\% of sigmoidectomies were laparoscopic and $91 \%$ open. Results: The requirement for single-use equipment in laparoscopic procedures increases the expense. However, after adding up all other costs, surprisingly, differences between the costs of laparoscopic and open procedures ranged from 451 PLN/€ 114 for laparoscopic operations to 611 PLN/€ 153 for open operations.

Conclusions: Laparoscopic cholecystectomy, considered the standard surgery for treating gallbladder diseases, is cheaper than open cholecystectomy. Laparoscopic appendectomy and sigmoidectomy are safe methods of minimally invasive surgery, slightly more expensive than open operations. Of all the analyzed procedures, one-day laparoscopic cholecystectomy is the most profitable. The costs of both laparoscopic and open sigmoidectomy are greatly underestimated in Poland.
\end{abstract}

Key words: laparoscopy, cholecystectomy, appendectomy, costs of treatment, open surgery, sigmoidectomy.

\section{Introduction}

Laparoscopy has been a standard procedure offered for many years by most medical centres providing surgical services in Poland. The number of laparoscopic procedures is steadily increasing, as is their range. For some time, laparoscopic procedures have been successfully applied in the treatment of acute cases, such as acute cholecystitis and acute appendicitis [1-3], and minimally invasive techniques, such as exploratory laparoscopy, are increasingly used in diagnostics $[4,5]$. The development of videoscopy also allows for the treatment of neoplastic diseases. While the surgical team always considers the clinical condition of the patient and concomitant disturbances, including their past surgical history, in choosing between the open or laparoscopic procedures [6], the cost of therapy is now also playing a more important role [7].

A laparoscopic procedure results in minimal interference in the condition and functioning of the patient, and the wound is as properly dressed as in an

\section{Address for correspondence}

Jacek A. Śmigielski MD, PhD, Department of Thoracic, General and Oncologic Surgery, Medical University of Lodz,

113 Zeromskiego St, 90-549 Lodz, Poland, phone: +48 4263935 21, e-mail: smiglo@mp.pl 
open procedure. A smaller post-operative wound reduces post-operative pain, which in turn contributes to a lower risk of infection and post-operative hernia [8]. Shorter hospitalization time and post-operative recovery might also reduce treatment costs [9].

\section{Aim}

The aim of the study is to present the total real costs of open and laparoscopic cholecystectomy, appendectomy and sigmoidectomy.

\section{Material and methods}

Between 1 May 2010 and 30 March 2014 in the Department of Thoracic Surgery, General and Oncological Surgery, Medical University of Lodz, and the Department of General Surgery of the Saint John of God Hospital, Lodz, 1404 cholecystectomies, 393 appendectomies and 88 sigmoidectomies were performed. In total, $97 \%$ of the cholecystectomy procedures were laparoscopic operations and 3\% were open operations. Similarly, $18 \%$ of appendectomies were laparoscopic and $82 \%$ were open, and $9 \%$ of sigmoidectomies were laparoscopic and $91 \%$ were open. In patients who underwent cholecystectomy, a laparoscopic procedure was standard. In more than ten patients, doctors performed open surgery due to prior surgical history, confirmed complicated acute cholecystitis or suspected gallbladder cancer. Although an open procedure was commonly used for appendectomy until 2011, since then some surgeons have been taking a laparoscopic approach. Likewise, laparoscopic sigmoidectomy is a relatively new procedure in Poland [10,11], with operations of this type only being performed since 2013, but only in selected patients. To simplify the following analysis, the following exchange rate was adopted: $€ 1=4$ PLN.

Cost analysis:

- average price of threads = 8 PLN/€ 2 per piece;

- hospital stay in the University Teaching Hospital Central Veterans' Hospital in Lodz = 320 PLN/€ 80;

- cost of a surgeon in the operating theatre per hour = 100 PLN/€ 25 gross;

- the cost of work in the operating theatre was calculated according to the following formula:

1 hour of work of the operating theatre $=1$ month of work of the operating block (the total time of all procedures/number of operating theatres)/ maintenance costs of the operating block (elec- tricity + personnel + indirect costs $)=360$ PLN/ $€ 90$;

- average operation time was calculated from operative reports;

- the cost of a single use of a reusable trocar was calculated by dividing its price (800 PLN/€ 200) by the average number (around 300) of laparoscopic procedures performed with the trocar in a period of a year = 2.60 PLN/€ 0.65;

- the cost of a single use of a grasper or reusable scissors was calculated by dividing their price (1800 PLN/€ 450) by the average number (around 300) of laparoscopic procedures performed in a period of a year = $6 \mathrm{PLN} / € 1.50$;

- the cost of a single use of a grasper was calculated by dividing its price ( 2000 PLN/€ 500) by the average number of procedures performed with the grasper in a period of two years $=3.30 \mathrm{PLN} / € 0.83$;

- the cost of a single use of a laparoscopic tower was calculated by dividing its price $(225,000$ PLN/ $€ 56,250$ ) by a 5 -year depreciation period and the average number of performed procedures: $225,000 /$ $(5$ years $\times 300$ procedures $)=150 \mathrm{PLN} / € 37.5$

\section{Results}

The need for single-use equipment in laparoscopic procedures adds to the cost of the procedures. However, after adding up all other costs, the final results were surprising, with the differences between the costs of laparoscopic and open procedures ranging from 451 PLN/€ 113 for laparoscopic operations to 611 PLN/€ 153 for open operations, with a wide range of differences for each type of procedure: for appendectomy, the open procedure is $7.8 \%$ less expensive than laparoscopy, but for cholecystectomy, the open procedure is $28.6 \%$ more expensive than laparoscopy. While the cost of laparoscopic and open sigmoidectomies appear to be comparable, the latter is $8.9 \%$ cheaper. All the performed calculations are presented in Tables I-IV.

\section{Discussion}

Most public health care centres face financial problems. The financial outcome of a centre is not often related to its personnel or work organization but potential financial problems result from underestimating the cost of surgical procedures funded by the NFZ (public health service). This study analysed the three most common surgical procedures 
Table I. Costs of open and laparoscopic appendectomy

\begin{tabular}{|c|c|c|c|c|}
\hline Parameter & $\begin{array}{c}\text { No. } \\
\text { open/lap }\end{array}$ & $\begin{array}{l}\text { Open surgery } \\
\text { [PLN/EURO] }\end{array}$ & $\begin{array}{l}\text { Laparoscopy } \\
\text { [PLN/EURO] }\end{array}$ & Notes \\
\hline Hospital stay [days] & $1.9 / 1.3$ & $608 / 152$ & $416 / 104$ & \\
\hline Surgical team & $2 / 2$ & $140 / 35$ & $182 / 46$ & \\
\hline Operation time [min] & $42 / 55$ & $252 / 63$ & $330 / 82.5$ & \\
\hline Trocar 12 mm & $0 / 2$ & $0 / 0$ & $5.20 / 1.30$ & \\
\hline Trocar $5 \mathrm{~mm}$ & $0 / 1$ & $0 / 0$ & $2.60 / 0.65$ & \\
\hline Threads & $4^{\star}(1-4) / 2^{\star}(4-5)$ & $32 / 8$ & $16 / 4$ & $\begin{array}{l}\text { *1. Peritoneal stitch } \\
\text { *2. Fascial stitch } \\
\text { *3. Subcutaneous stitch } \\
\text { *4. Dermal stitch } \\
\text { *5. Roeder loop }\end{array}$ \\
\hline Grasper 5 mm & $0 / 3$ & $0 / 0$ & $18 / 4.5$ & Scissors included \\
\hline Laparoscopic tower & $0 / 1$ & $0 / 0$ & $150 / 38$ & Optics included \\
\hline Total & & $1,032 / 258$ & $1,120 / 280$ & \\
\hline
\end{tabular}

Table II. Costs of open and laparoscopic cholecystectomy

\begin{tabular}{|c|c|c|c|c|}
\hline Parameter & $\begin{array}{c}\text { No. } \\
\text { open/lap }\end{array}$ & $\begin{array}{l}\text { Open surgery } \\
\text { [PLN/EURO] }\end{array}$ & $\begin{array}{l}\text { Laparoscopy } \\
\text { [PLN/EURO] }\end{array}$ & Notes \\
\hline Hospital stay [days] & $2.4 / 1.4$ & $768 / 192$ & $448 / 112$ & \\
\hline Surgical team & $3^{*} / 2$ & $348 / 87$ & $160 / 40$ & $\begin{array}{l}{ }^{*} 1 \text { surgeon or automated } \\
\text { retractor }\end{array}$ \\
\hline Operation time & $1 \mathrm{~h} 10 \mathrm{~min} / 48 \mathrm{~min}$ & $420 / 105$ & $288 / 72$ & \\
\hline Trocar $12 \mathrm{~mm}$ & 2 & $0 / 0$ & $5.20 / 1.30$ & \\
\hline Trocar $5 \mathrm{~mm}$ & 1 & $0 / 0$ & $2.60 / 0.65$ & \\
\hline Threads & $5^{\star}(1-5) / 3^{\star}(1+3+5)$ & $40 / 10$ & $16 / 4$ & $\begin{array}{l}\text { *1. Peritoneal stitch } \\
\text { *2. Muscular stitch } \\
\text { *3. Fascial stitch } \\
\text { *4. Subcutaneous stitch } \\
\text { *5. Dermal stitch }\end{array}$ \\
\hline Grasper 5 mm & 3 & $0 / 0$ & $18 / 4.5$ & $\begin{array}{l}\text { Hook and scissors } \\
\text { included }\end{array}$ \\
\hline Laparoscopic tower & 1 & $0 / 0$ & $150 / 37.50$ & Optics included \\
\hline Clip applicator & 1 & $0 / 0$ & $3.30 / 0.83$ & \\
\hline Clips & 1 pack -6 pieces & $0 / 0$ & $36 / 9$ & \\
\hline Total & & $1,578 / 394$ & $1,127 / 282$ & \\
\hline
\end{tabular}

performed using open and laparoscopic methods: cholecystectomy, appendectomy and sigmoidectomy. Both the direct cost of surgery and all the indirect costs incurred by the centre in order to provide patients with suitable therapy were included. The analysis does not include costs which are the same for the compared procedures, i.e.: 1) a set of reusable surgical instruments: clamps, pincers, scissors, peans, etc.; 2) sterilization of a set of surgical instruments; 3) preparing the patient and operative area; 4) anaesthetizing the patient; 5) draping the patient; 6) the cost of histopathological examination. 
Table III. Costs of open and laparoscopic sigmoidectomy

\begin{tabular}{|c|c|c|c|c|}
\hline Parameter & $\begin{array}{c}\text { No. } \\
\text { open/lap }\end{array}$ & $\begin{array}{l}\text { Open surgery } \\
\text { [PLN/EURO] }\end{array}$ & $\begin{array}{l}\text { Laparoscopy } \\
\text { [PLN/EURO] }\end{array}$ & Notes \\
\hline Hospital stay [days] & $4.4 / 3.8$ & $1,408 / 352$ & $1,216 / 304$ & \\
\hline Surgical team & $3 / 2$ & $515 / 129$ & $500 / 125$ & $\begin{array}{l}\text { *1 surgeon or automated } \\
\text { retractor }\end{array}$ \\
\hline Operation time & $1 \mathrm{~h} 45 \mathrm{~min} / 2 \mathrm{~h} 15 \mathrm{~min}$ & $630 / 157.50$ & $900 / 225$ & \\
\hline Trocar $12 \mathrm{~mm}$ & 2 & $0 / 0$ & $5.20 / 1,30$ & \\
\hline Trocar $5 \mathrm{~mm}$ & 2 & $0 / 0$ & $5.20 / 1,30$ & \\
\hline Threads & $7^{\star}(1-6) / 3^{\star}(1+3+5)$ & $56 / 14$ & $24 / 6$ & $\begin{array}{l}\text { *1. Peritoneal stitch } \\
\text { *2. Muscular stitch } \\
\text { *3. Fascial stitch } \\
\text { *4. Subcutaneous stitch } \\
\text { *5. Dermal stitch } \\
\text { *6 Garter stitch }\end{array}$ \\
\hline Grasper 5 mm & 5 & $0 / 0$ & $30 / 5$ & $\begin{array}{l}\text { Hook and scissors } \\
\text { included }\end{array}$ \\
\hline LigaSure 5 mm & 1 & $0 / 0$ & $1,800 / 450$ & \\
\hline LigaSure 10 mm & 1 & $1,600 / 400$ & $0 / 0$ & \\
\hline Laparoscopic tower & 1 & $0 / 0$ & $150 / 37.50$ & Optics included \\
\hline Reticular stapler & 1 & $0 / 0$ & $600 / 150$ & \\
\hline Stapler TA 60 & 1 & $450 / 112.50$ & $0 / 0$ & \\
\hline Clip applicator & 1 & $0 / 0$ & $3.30 / 0.83$ & \\
\hline Clips & 6 & $0 / 0$ & $36 / 9$ & \\
\hline Stapler CEEA & 1 & $1,620 / 405$ & $1,620 / 405$ & $\begin{array}{c}\text { Stitch fixing a stapler } \\
\text { head }\end{array}$ \\
\hline Total & & $6,279 / 1570$ & $6,890 / 1722$ & \\
\hline
\end{tabular}

Table IV. Total cost of all procedures

\begin{tabular}{|lcccc|}
\hline Procedure & $\begin{array}{c}\text { Price } \\
\text { [PLN/EURO] }\end{array}$ & \multicolumn{2}{c}{ National Health Fund } & \multirow{2}{*}{$\begin{array}{c}\text { Profit } \\
\text { [PLN/EURO] }\end{array}$} \\
\cline { 3 - 4 } & & Points & $\begin{array}{c}\text { Cost } \\
\text { [PLN/EURO] }\end{array}$ & \\
\hline Open appendectomy & $1,552 / 388$ & 47 & $2,444 / 611$ & $892 / 223$ \\
\hline Laparoscopic appendectomy & $1,640 / 410$ & 47 & $2,444 / 611$ & $804 / 201$ \\
\hline Open cholecystectomy & $2,098 / 524$ & 63 & $3,276 / 819$ & $1,178 / 295$ \\
\hline Laparoscopic cholecystectomy & $1,647 / 412$ & 57 & $2,964 / 741$ & $1,317 / 329$ \\
\hline Open sigmoidectomy & $6,799 / 1,700$ & 110 & $5,720 / 1,430$ & $-1,079 /-270$ \\
\hline Laparoscopic sigmoidectomy & $7,410 / 1,852$ & 110 & $5,720 / 1,430$ & $-1,690 /-423$ \\
\hline
\end{tabular}

The total cost of the above procedures is around 520 PLN/€ 130. Table IV presents the total cost of hospital treatment, including the procedures required for both open and laparoscopic methods.
When considering the costs of sigmoidectomy, it should be pointed out that the price of the most commonly used mechanical stapler, the CEEA $31 \mathrm{~mm}$, substantially increases the total cost of surgery, by 
$1,600 \mathrm{PLN} / € 400$. This equipment is used in both the open and laparoscopic methods.

All trocars used in the evaluated laparoscopic procedures are reusable, and their only replaceable part is a seal, which should be replaced after about 200 procedures. Undoubtedly, the application of single-use trocars would considerably increase the total cost of laparoscopic operations. Conversion is another factor contributing to an increase in the cost of surgery [12]. The costs of converted procedures will be subject to a separate analysis.

Open appendectomy was 88 PLN/€ 22 (7.8\%) cheaper than laparoscopic appendectomy, although based on financial settlements with the NFZ (public health service), both methods were found to be profitable: 892 PLN/€ 223 and 804 PLN/€ 201 respectively. Similarly, open sigmoidectomy is 611 PLN/ $€ 153$ cheaper (8.9\%) than laparoscopic surgery, despite longer post-operative hospitalization. The period of hospitalization after a laparoscopic procedure was reduced due to less acute post-operative pain, the application of a "fast track" recovery programme and the fact that the patients can regain their mobility more quickly [13]. Unfortunately, both methods incur losses for the medical centre performing the procedures: 1,079 PLN/€ 270 for the open surgery and 1,690 PLN/€ 422 for the laparoscopy. In contrast, laparoscopic cholecystectomy is 451 PLN/ $€ 113$ (28.6\%) cheaper than open cholecystectomy, and both methods are profitable for the centre, earning 1317 PLN/€ 329 for the laparoscopy and 1178 PLN/€ 295 for the open procedure.

However, the techniques used in operations are constantly changing. "Single-incision" methods, which are now quite common, are more expensive than standard laparoscopy [14] and represent another challenge for surgeons. The question is whether the NFZ (public health service) will correctly estimate the cost of these innovative procedures.

\section{Conclusions}

Laparoscopic cholecystectomy, considered the standard surgical procedure in treating gallbladder diseases, is cheaper than open cholecystectomy. Laparoscopic appendectomy and sigmoidectomy are safe methods of minimally invasive surgery which are only slightly more expensive than open operations. Of all the analyzed procedures, one-day laparoscopic cholecystectomy is the most profitable for the centre. The costs of both laparoscopic and open sigmoidectomy are greatly underestimated in Poland.

\section{Conflict of interest}

The authors declare no conflict of interest.

\section{References}

1. Gans SL, Pols MA, Stoker J, et al. Guideline for the diagnostic pathway in patients with acute abdominal pain. Dig Surg 2015; 32: 23-31.

2. Bozkurt MA, Unsal MG, Kapan S, et al. Is laparoscopic appendectomy going to be standard procedure for acute appendicitis: a 5-year single center experience with 1,788 patients. Eur J Trauma Emerg Surg 2015; 41: 87-9.

3. Koti RS, Davidson CJ, Davidson BR. Surgical management of acute cholecystitis. Langenbecks Arch Surg 2015; 400: 403-19.

4. Jayakrishnan TT, Zacharias AJ, Sharma A, et al. Role of laparoscopy in patients with peritoneal metastases considered for cytoreductive surgery and hyperthermic intraperitoneal chemotherapy (HIPEC). World J Surg Oncol 2014; 12: 270.

5. Papparella A, Nino F, Noviello C, et al. Laparoscopic approach to Meckel's diverticulum. World J Gastroenterol 2014; 20: 8173-8.

6. Koh FH, Wong J, Tan JK, et al. Laparoscopic colorectal surgery is safe and benefits octogenarian patients with malignant disease: a matched case-control study comparing laparoscopic and open colorectal surgery. Int I Colorectal Dis 2015; 30: 963-8.

7. Matyja M, Strzałka M, Zychowicz A, et al. Single-incision laparoscopic cholecystectomy - can we afford that? Cost comparison of different surgical techniques. Pol Przegl Chir 2014; 86: 177-80.

8. Andersson RE. Short-term complications and long-term morbidity of laparoscopic and open appendicectomy in a national cohort. Br J Surg 2014; 101: 1135-42.

9. Keller DS, Lawrence JK, Nobel T, et al. Optimizing cost and shortterm outcomes for elderly patients in laparoscopic colonic surgery. Surg Endosc 2013; 27: 4463-8.

10. Olakowski M, Jabłonska B, Braszczok L, et al. Distal pancreatectomy - own experience. Pol Przegl Chir 2012; 84: 298-303.

11. Golebiewski A, Czauderna P. The role of laparoscopy in the management of pediatric appendicitis: a survey of Polish pediatric surgeons. Videosurgery Miniinv 2015; 10: 101-6.

12. Cauchy F, Fuks D, Nomi T, et al. Risk factors and consequences of conversion in laparoscopic major liver resection. Br J Surg 2015; 102: 785-95.

13. Sosada K, Wiewióra M, Piecuch J, et al. Fast track in large intestine surgery - review of randomized clinical trias. Videosurgery Miniinv 2013; 8: 1-7.

14. Islam S, Adams SD, Mahomed AA. SILS: is it cost- and time-effective compared to standard pediatric laparoscopic surgery? Minim Invasive Surg 2012; 2012: 807609.

Received: 21.04.2015, accepted: 19.06.2015. 